\title{
Does a Creative Learning Medium Matter? Impact of Low Cost Android Tablets on Elementary Students' English Comprehension, Perceived Performance and Memory Retention
}

\author{
Ibrahim El-Mouelhy ${ }^{1}$, Issac Hin Chun Poon ${ }^{1}$, Anna Na Na Hui ${ }^{2}$, Christina Sue-Chan ${ }^{3}$ \\ ${ }^{1}$ ThinkBlaze, Hong Kong, China \\ ${ }^{2}$ Department of Applied Social Studies, City University of Hong Kong, Hong Kong, China \\ ${ }^{3}$ Department of Management, City University of Hong Kong, Hong Kong, China \\ Email: ibrahim@outblaze.com, annahui@cityu.edu.hk
}

Received September $24^{\text {th }}, 2013$; revised October $24^{\text {th }}, 2013$; accepted November $1^{\text {st }}, 2013$

\begin{abstract}
Copyright (c) 2013 Ibrahim El-Mouelhy et al. This is an open access article distributed under the Creative Commons Attribution License, which permits unrestricted use, distribution, and reproduction in any medium, provided the original work is properly cited. In accordance of the Creative Commons Attribution License all Copyrights (C) 2013 are reserved for SCIRP and the owner of the intellectual property Ibrahim El-Mouelhy et al. All Copyright (C) 2013 are guarded by law and by SCIRP as a guardian.
\end{abstract}

\begin{abstract}
Introduction: Android tablet is a relatively newer and cheaper portal electronic device that can be used as a creative learning tool in elementary school setting compared with laptop. However, the effect of Android tablet on students' learning performance has been rarely studied. Before encouraging schools to implant Android tablet in teaching process, it should be ensured that tablet should at least do no harm on students' academic performance. This research aims to investigate the impact of an innovative medium - a low cost Android tablet versus paper - on elementary students' reading comprehension, perceived comprehension performance, and memory retention, and discuss about the implication of the finding and future directions. Method: In Study 1, 18 fourth-graders and 36 sixth-graders read 2 grade-appropriate passages on either a tablet or paper and completed related comprehension tests, then assessed their perceived performance. In Study 2, 16 first-graders attempted to memorize 25 pictures displayed on tablets while another 12 first-graders attempted to memorize 25 pictures displayed on paper. After 1 minute filler activity, participants were shown 50 pictures and asked to identify those they had attempted to memorize. Results: In Study 1, results showed that fourth-graders comprehended better when reading on paper, whereas sixth-graders scored similarly on both media. An interaction effect between "medium" and "gender" was found in the perceived performance of fourth-graders, with boys reporting higher perceived performance when using tablets. In Study 2, first-graders experienced better memory retention when they viewed pictures on paper. Conclusion: The introduction of Android tablets in the classroom did not have a significant negative impact on sixth-graders' reading comprehension. However, some caution is required when introducing tablets to first-graders and fourth-graders because of the negative effect found in this study. It should also be noted that the use of tablets may enhance the confidence of grade 4 boys during comprehension tasks, but the confidence of grade 4 girls engaged in the same activities may be deteriorated.
\end{abstract}

Keywords: Reading Comprehension; Perceived Performance; Memory Retention; ICT; Android Tablet

\section{Introduction}

Technology is a part of all aspects of modern lifestyles, and high technology is ubiquitous in developed countries. In February 2000, Bill Gates spoke to teachers in London about the Microsoft project "Anytime, Anywhere Learning" (BBC News, 2000). The initiative recommended that every pupil in the United Kingdom should have direct personal access to a laptop computer in order to utilize the educational potential of the technology. According to Mr. Gates, learning is no longer confined within the traditional boundaries of the classroom (BBC News, 2000: para. 8). Mr. Gates claimed that an e-learning revolution would change the world of education (Lucas, 2001). Today, technology is indeed used in the classroom with the aim to enhance students' learning processes. Technology in education is commonly referred to as "technology enhanced learning" (Dror, 2008) or, used in more general terms, "information and communication technologies" (Bordbar, 2010). In a review of the education reforms across four Asian Chinese societies, the use of technology as an innovative medium for enhancement of creativity in education and curriculum is well documented (Hui \& Lau, 2010).

Although the effect of technology on academic performance, especially reading comprehension, has been studied for many years, it is still unclear to what degree ICTs affect learning and student performance. In the late 1990s, Kathryn Matthew conducted a frequently cited study to establish the effectiveness of TEL. Matthew (1997) recruited 30 third-grade US elementary students ( 15 boys and 15 girls) as participants and measured 
their comprehension scores by asking students to retell a story after they used a personal computer to read stories stored on a CD-ROM, and also after students read similar stories from print books. According to Matthew (1997), "story-retellings provided an opportunity to analyze the active processing and unique understanding of the texts created by students as they read electronic texts" (p. 270). She found that students scored higher in comprehension when reading CD-ROM materials than when reading from a printed book. She offered the following explanation for the difference in results between the two media: "CD-ROM storybooks provide a multisensory learning experience that enables students to literally interact with the text and illustrations and to actively process the text, both of which lead to a personal understanding of the text" (Matthew, 1997: p. 269). Her study suggested that ICT had a positive effect on students' reading comprehension.

High technology evolves at a rapid pace, and it is possible that its effects on various aspects of a student's performance have also changed in the 15 years since Matthew's study. We reviewed more recent research on the topic of how ICT affected reading comprehension, and found that the positive impact originally reported by Matthew (1997) seemed to have subsided to a neutral or even negative effect. Grimshaw, Dungworth, McKnight, and Morris (2006) conducted a study using 132 students aged 9 to 11 years as participants and concluded that the reading comprehension scores of children who read stories on CD-ROM were not significantly different from the scores of children who read print versions of the same stories. Kang, Wang, and Lin (2009) recruited 10 male and 10 female junior college students for an experiment to test reading performance when reading electronic books on personal digital assistants (PDA) versus reading performance of the same content on conventional printed books. The students in Kang et al.'s (2009) study were assessed on reading performance using a combination of reading speed and accuracy. Reading speed was not a direct concern in our investigation, so we focused on Kang et al.'s (2009) reading accuracy results, which were similar to Grimshaw et al.'s (2006) study: there was no statistically significant difference in correct recall between reading electronically and reading on print books. More recently, Jones and Brown (2011) conducted experiments with third-grade children to measure reading comprehension when reading an ordinary print book and e-books on computer delivered via the RazKids.com website; the researchers found that the "e-book format [viewed on a PC] did not significantly increase comprehension" (Jones \& Brown, 2011: p. 19). Grace (2011) and Stewart (2012) conducted similar experiments on third-graders and second-graders, respectively, with even newer technology: the popular Apple iPad tablet. Results pointed to neither a positive nor negative effect on reading comprehension when participants read a text using an iPad instead of reading a text in print. Our review of the recent literature suggests that electronic media do not appear to be more effective learning tools or aides than traditional print media.

Of serious concern is the existence of recent research indicating that ICT may have a negative impact on reading comprehension among some students. Sheppard (2011) separated 46 sixth-grade participants aged 11 to 13 years into "three separate groups (low, middle and high) based on their achievement in reading comprehension" (p. 13) and found that using an iPad was linked to a decrease in the reading comprehension scores of participants in the low achievement group (no differences at- tributable to reading medium were noted for the middle and high achievement groups). Furthermore, a recent study conducted by Jeong (2012) on 56 sixth-grade Korean public school students aged 10 to 12 years noted a significant "book effect" on reading comprehension scores; compared against reading a text from a PDF file using a personal computer, "p-books [print books] appeared to enable better reading comprehension" (Jeong, 2012: p. 400). Jeong (2012) gave a possible explanation that "reading on a screen might require more concentration than on paper, and e-book reading is more error prone than p-book reading" (p. 402).

Most of the above studies compared the computer display of a particular screen size with the paper display. The displays included a PDA (8.5 inches diagonal in Kang et al.'s (2009) study), iPad tablet (9.7 inches diagonal in Grace's (2011) study), and computer screen (17 inches diagonal in Jeong's (2012) study. In a study conducted by Ozok, Benson, Chakraborty and Norcio (2008), participants completed 4 different tasks (reading, writing/typing, direct manipulation, and form filling) using computer displays of different sizes (both tablets and laptops) or pen-and-paper. Results indicated that college students perceived the laptop screen to be significantly better for reading than the tablet screen. The perceived abilities to perform the reading task effectively and efficiently were significantly higher for pen-and-paper medium than for laptop and tablet displays. Post hoc comparison further showed that college students perceived their reading abilities to be significantly higher when using pen-and-paper than when using tablet displays. Overall satisfaction with the reading task and perceived low number of errors were similar for the tablet, laptop and pen-and-paper media. Ozok et al. (2008) concluded that the study of tablets as a reading medium presented a promising area for investigation.

The reported beneficial effects of ICT on children's reading comprehension do not seem to have kept up with the progress of technology since the 1990s, and in the recent decade ICT appears to have a neutral or even a negative effect on reading comprehension performance. We set out to investigate the effect of low cost tablet computing devices on elementary school students' reading comprehension, perceived performance, and memory retention. Outblaze and Animoca, two Hong Kongbased technology companies, sponsored the study with the aim to kickstart "a social programme designed to reduce the digital divide and assess the impact of tablet devices in the learning environment" (Animoca, 2012: p. 1). Outblaze and Animoca maintain that the key to bridging the digital divide is low cost technology (e.g., see One Laptop Per Child and One Tablet Per Child initiatives). The two companies donated 49 low cost Android tablets to Chan's Creative School (Hong Kong Island); the devices (Ainol Novo 7 Paladin) cost HK\$ 590 (about US\$ 76) each at the time and were selected and provided by the sponsors, who suggested we study the effects of the technology on the school's students. The number of devices donated was sufficient to allow every elementary student in the school to have regular access to and utilize a current Android 4.0 ("Ice Cream Sandwich") 7-inch diagonal tablet device. The school allowed us to observe and test the performance of students over a period of a month and a few days.

After one month, during which students regularly used the tablet in English class, we tested elementary students' reading comprehension performance to determine any effects associated with the introduction of the tablets into the classroom. Because the literature on this topic does not appear to be conclusive, we 
utilize the following hypothesis:

Hypothesis 1-Elementary students' English reading comprehension performance is higher when subjects read on print media than when they read on low cost Android tablets.

We also measured how well the students thought they had performed in the reading comprehension tests. In order to maintain consistency with hypothesis 1 , and because the literature predicts a positive effect, we utilized the following hypothesis to identify differences in self-reported performance when reading on the two different media:

Hypothesis 2-Elementary students' perceived performance in English reading comprehension tests is higher when subjects read on print media than when they read on low cost Android tablets.

In addition to reading comprehension, we also explored the impact on the students' memory retention. The effect of ICT on memory retention was investigated in 1998 by Dede, suggesting that "the use of computers in education can generally help to improve memory retention" (as cited in Wheeler, 2001: p. 8). Ando and Ueno (2010) suggested, on the basis of a fairly complex study, that the use of tablet PCs could improve students' memory retention; specifically, they found that memory retention was improved when participants reading material on a personal computer used a pen tablet PC to take notes. Gasparini and Culén (2012) found that when using an iPad both children with and without prior reading difficulties showed a slight improvement in memory retention after reading a text, although the sample size in that study was quite small. Based on the existing literature, in this study we decided to examine the effect of low cost tablet devices on elementary students' memory retention with the following hypothesis:

Hypothesis 3-Elementary students experience better memory retention when they view materials on low cost Android tablets than when they view materials on print media.

\section{Study 1}

\section{Method}

\section{Subjects}

This study comprised grade 4 students and grade 6 students from Chan's Creative School (Hong Kong Island). Chan's Creative School (Hong Kong Island) is a public elementary school in Hong Kong. The school already possessed 50 aging computers for student use and enjoyed a moderately high computer-to-student ratio (about 1:3 for the entire school), but it lacked additional funding for mobile information technology equipment such as tablet computers. Outblaze and Animoca donated 49 7-inch Android 4.0 tablets (Ainol Novo 7 Paladin) to the school in order to update the school's mobile ICT equipment, which provided the opportunity to conduct this research.

There were 18 grade 4 students (11 boys and 7 girls) aged between 9 and 12 years with $M=10.50$ and $S D=0.92$. There were 36 grade 6 students ( 17 boys and 19 girls) aged between 11 and 16 years with $M=12.53$ and $S D=0.97$. All participants had made regular individual use of the tablets for one month in the course of daily class activities. The majority of participants (about $70 \%$ ) had never used tablet technology before, and all of them were new to the use of tablets for classroom learning.

\section{Instruments}

Four English reading comprehension tests were used in this study, two for each grade. The contents and questions of the two tests in each grade were different but they were similar in reading level and difficulty, and contained the same number of questions. The tests for each class were selected by teachers to be grade-appropriate and of similar difficulty. For grade 4 students, the passage in the first test contained 249 words, while the passage in the second test contained 216 words; both these tests contained five multiple-choice questions and three short questions (question 6 in both tests included two questions). The highest possible score for both tests for grade 4 students was 8 . For grade 6 students, the passage in the first test contained 213 words, while the passage in the second test contained 160 words; both these tests contained four multiple-choice questions and four short questions. The highest possible score for both tests for grade 6 students was 8 .

After a reading comprehension test, participants were asked to complete perceived performance questionnaires (adapted from Baker, 2010) to describe how well they thought they had performed. The questionnaires consisted of five questions presented in a 6-point Likert scale to measure how well participants "believed they did on each of the formats [media] and their emotional reaction to those formats" (Baker, 2010: p. 22). The original questionnaire treats with the following media: paper, iPod, and Kindle. To adapt the questionnaire to our study we changed the word "iPod" to "tablet" and removed "Kindle". The questionnaire was translated into Chinese for the convenience of participants. Cronbach's $\alpha$ of the perceived performance questionnaire in this study were .76 and .82 for tablet and paper, respectively, indicating a good level of reliability.

\section{Procedure}

Before the experiment started, we obtained informed consent from the school to perform the study with grade 4 and 6 students as participants. All procedures discussed in this study were conducted under the guidance of at least one teacher present in the classroom at all times. For the first comprehension test, all participants read a passage in English on the tablet and answered questions about it on a printed test sheet. After finishing the first test, all participants were asked to fill out the perceived performance questionnaire to assess how well they believed they had performed. For the second comprehension test, all participants read a passage in English on printed paper and answered questions about it on a printed test sheet. After finishing the second test, all participants were asked to fill out the perceived performance questionnaire to assess how well they believed they had performed. All received data were used exclusively for the purposes of the current research and kept in strict confidentiality; participating students remained anonymous to researchers. Students' names were not recorded. Data that included any personal identifiers (such as class or class number or handwriting) were destroyed after the results of each procedure were recorded.

\section{Statistical Analysis}

Two two-way mixed-design Analyses of Variance (ANOVAs) were conducted to examine the effects of "medium" (tablet or paper) and "gender" on reading comprehension score and perceived performance, allowing us to examine the interaction effect between "medium" and "gender". In each ANOVA, either comprehension score or perceived performance was entered as a dependent variable, while "medium" was entered as 
within-subject independent variable and "gender" was entered as between-subject independent variable. An alpha level of .05 was used for all results; any $p$-values larger than .05 obtained after conducting ANOVAs were considered to be non-significant. Partial $\eta 2$ is reported if the effects are found to be significant.

\section{Results}

\section{Grade 4 Students}

Table 1 shows the means and standard deviations of each score in each condition.

Participants reading the passage on paper had significantly higher reading comprehension scores than participants reading the passage on tablet $\left(F(1,16)=19.40, p<.001\right.$, partial $\eta^{2}$ $=.55)$. For the main effect of "gender" on comprehension score, it was found that $F(1,16)=3.59$ with $p=.076$. Although this $p$-value is smaller than .10 , which could be considered marginally significant, we utilized a limit of .05 to avoid potential problems resulting from the limited sample sizes. Therefore, since the observed $p$-value was larger than .05 , we concluded that there was no main effect for "gender". The interaction effect between "medium" and "gender" on comprehension scores was also statistically non-significant $(F(1,16)=2.57, p$ $=.129)$, meaning that the effect of "medium" was not moderated by the effect of "gender" and vice versa.

There were no significant main effects of "medium" and "gender" on the perceived performance scores for grade 4 students (for "medium": $F(1,16)=0.11, p=.747$; for "gender": $F(1,16)=2.75, p=.117)$. However, a significant interaction effect was found on the perceived performance scores $(F(1,16)$ $=7.51, p=.015$, partial $\eta^{2}=.32$ ). This significant interaction effect suggested that the effect of "medium" was moderated by the effect of "gender" and vice versa. Figure 1 shows the means plot to illustrate the interaction effect visually. Boys perceived themselves to perform better when reading on tablet while girls perceived themselves to perform better when reading on paper. However, both boys and girls had similar perceived performance scores when reading on tablet.

\section{Grade 6 Students}

The means and standard deviations of each score in each condition are shown in Table 2. Results of the two two-way mixed design ANOVAs showed that there were no significant main effects of "medium" and "gender" and interaction effect on both comprehension scores (for "medium": $F(1,34)=0.88, p$ $=.355$; for "gender": $F(1,34)=1.29, p=.263$; for interaction: $F(1,34)=1.75, p=.195)$ and perceived performance (for "medium": $F(1,34)=1.01, p=.322$; for "gender": $F(1,34)=0.09$, $p=.769$; for interaction: $F(1,34)=1.55, p=.221)$.

\section{Discussion}

\section{Comprehension Score}

Our Hypothesis 1 was confirmed for grade 4 students, because their scores in English reading comprehension were lower when reading on tablet than on paper. This result is consistent with a number of previous studies that suggested that ICTs decrease children's reading performance (see Jeong, 2012; Sheppard, 2011). Apart from Jeong's (2012) explanation stated in our introduction, another possible explanation is that children were more accustomed to reading on paper than on tablet (Kang et al., 2009). Participants in our study had years of experience reading and being tested on the medium of paper, whereas their exposure to tablets in the classroom amounted to a month and a few days. It is reasonable to speculate that students' lower performance when using tablets may be partly attributable to lack of habituation to the devices.

Hypothesis 1 was rejected for grade 6 students, who showed no significant difference in comprehension scores when reading on tablet or on paper. This result is similar to Grace's (2011) and Stewart's (2012) studies, although those researchers utilized Apple iPads instead of low cost Android devices. Grace and Stewart both found that reading on iPad had no significant effect on comprehension versus reading on paper, which is consistent with our results for grade 6 students.

The lack of consistency between results for grade 4 and grade 6 students is puzzling. It is possible that, as students age or advance to a higher grade, their performance in reading comprehension is diminishingly affected by ICT. Our study did determine that gender did not alter the effect of tablet use on reading comprehension among grade 4 and 6 students, but further investigation is required to explore additional factors (such as the roles played by a participant's age and grade).

\section{Perceived Performance}

Although ANOVA results showed that there was no main effect of "medium" and "gender" on perceived performance for

Table 1.

Means, standard deviations, and analysis of variance (ANOVA) results for comprehension scores and perceived performance as a function of gender and medium for grade 4 students.

\begin{tabular}{|c|c|c|c|c|c|c|c|}
\hline \multirow[b]{3}{*}{ Medium } & \multicolumn{4}{|c|}{ Gender } & \multicolumn{3}{|c|}{ ANOVA $F(1,16)$} \\
\hline & \multicolumn{2}{|c|}{ Boys $(n=11)$} & \multicolumn{2}{|c|}{ Girls $(n=7)$} & \multirow{2}{*}{$\begin{array}{c}\text { Between subjects } \\
\text { Gender (G) }\end{array}$} & \multicolumn{2}{|c|}{ Within subjects } \\
\hline & $M$ & $S D$ & $M$ & $S D$ & & Medium (Me) & $\mathrm{G} \times \mathrm{Me}$ \\
\hline Comprehension Scores $^{\mathrm{a}}$ & & & & & 3.59 & $19.40 * *$ & 2.57 \\
\hline Reading on tablet & 2.82 & 1.40 & 3.57 & 2.23 & & & \\
\hline Reading on paper & 3.82 & 1.25 & 5.71 & 1.80 & & & \\
\hline Perceived Performance ${ }^{b}$ & & & & & 2.75 & 0.11 & $7.51^{*}$ \\
\hline Reading on tablet & 3.51 & 1.11 & 3.57 & 0.99 & & & \\
\hline Reading on paper & 2.75 & 1.15 & 4.17 & 0.88 & & & \\
\hline
\end{tabular}

Notes. ${ }^{\mathrm{a}}$ Comprehension scores ranged from 0 to 8 , higher score indicates better comprehension result. ${ }^{\mathrm{b}}$ Perceived performance ranged from 1 to 6 , higher score indicates better perceived performance. ${ }^{*} p<.05 .{ }^{*} p<.001$. 


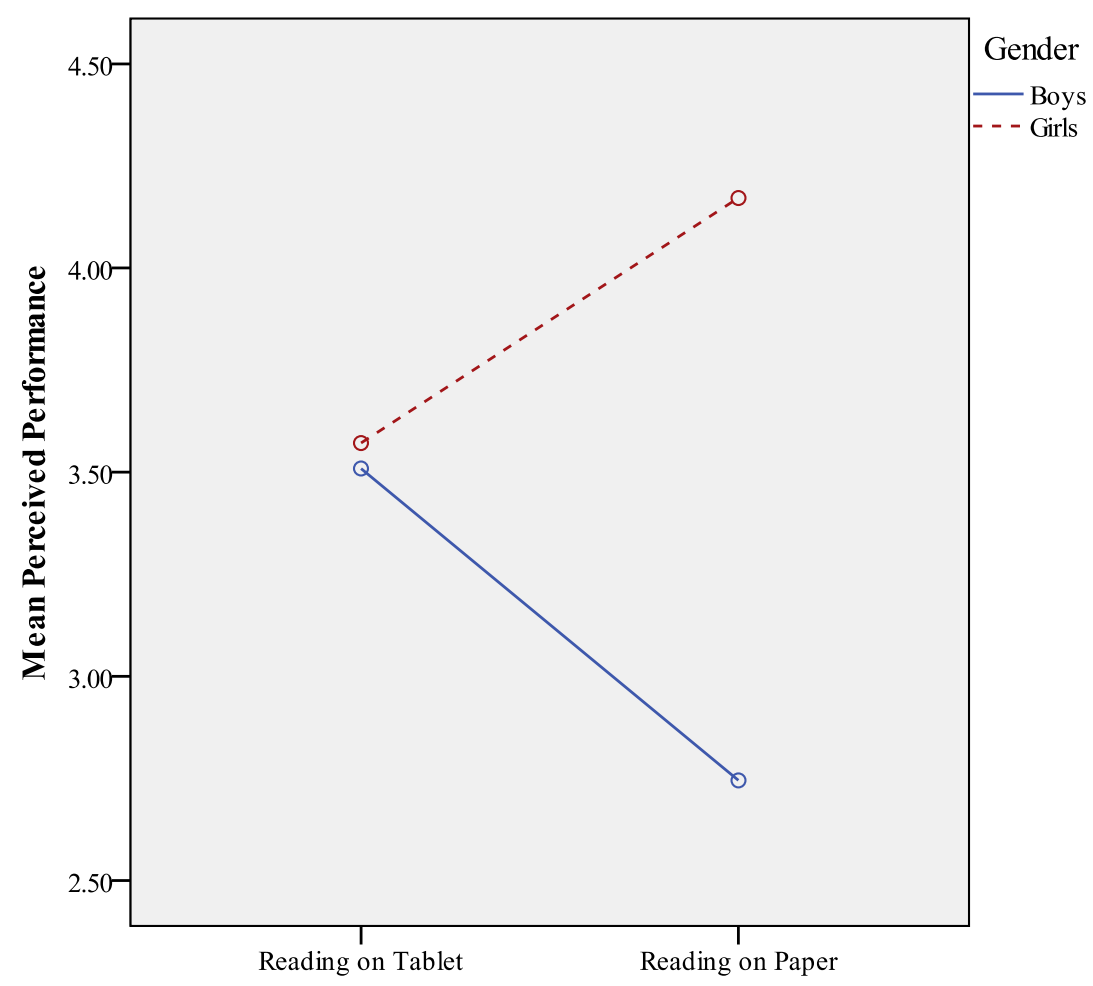

Medium

Figure 1.

Means plot of perceived performance score by medium across two gender groups for grade 4 students.

Table 2.

Means, standard deviations, and analysis of variance (ANOVA) results for comprehension scores and perceived performance as a function of gender and medium for Grade 6 students.

\begin{tabular}{|c|c|c|c|c|c|c|c|}
\hline \multirow[b]{3}{*}{ Medium } & \multicolumn{4}{|c|}{ Gender } & \multicolumn{3}{|c|}{ ANOVA $F(1,34)$} \\
\hline & \multicolumn{2}{|c|}{ Boys $(n=17)$} & \multicolumn{2}{|c|}{ Girls $(n=19)$} & \multirow{2}{*}{$\begin{array}{c}\text { Between subjects } \\
\text { Gender }(\mathrm{G})\end{array}$} & \multicolumn{2}{|c|}{ Within subjects } \\
\hline & $M$ & $S D$ & $M$ & $S D$ & & Medium (Me) & $\mathrm{G} \times \mathrm{Me}$ \\
\hline Comprehension Scores ${ }^{\mathrm{a}}$ & & & & & 1.29 & 0.88 & 1.75 \\
\hline Reading on tablet & 3.32 & 1.89 & 4.26 & 1.50 & & & \\
\hline Reading on paper & 3.94 & 1.75 & 4.16 & 1.77 & & & \\
\hline Perceived Performance & & & & & 0.09 & 1.01 & 1.55 \\
\hline Reading on tablet & 3.88 & 0.65 & 3.79 & 0.73 & & & \\
\hline Reading on paper & 3.59 & 1.17 & 3.82 & 0.59 & & & \\
\hline
\end{tabular}

Note. ${ }^{\mathrm{a}}$ Comprehension scores ranged from 0 to 8 , higher score indicates better comprehension result. ${ }^{\mathrm{b}}$ Perceived performance ranged from 1 to 6 , higher score indicates better perceived performance.

grade 4 students, a significant interaction between "medium" and "gender" was found. Figure 1 shows the means of perceived performance by medium across two gender groups for grade 4 students, and leads us to reject Hypothesis 2 for males and accept it for female grade 4 students. The effect of "medium" was canceled by the effect of "gender" because male students thought that they would perform better in comprehension tasks when reading on tablet than when reading on paper, whereas female students perceived the reverse. We speculate this may be because boys tend to have higher self-efficacy in computer skills whereas girls tend to have more negative atti- tudes towards computers (Broos, 2005). Two pairs of researcher, Barker and Aspray as well as Volman and van Eck, have suggested that "boys have more opportunities to experience success with ICTs, and, therefore, they are more likely to develop positive beliefs" (as cited in Vekiri, 2010: p. 17).

If the above explanation is valid, then the male participants in our study ought to have scored better in perceived performance when reading on tablets than females, which was not the case: boys and girls had similar perceived performance when reading on tablets. We propose the following explanation to account for these results: although boys tend to have higher 
self-efficacy in technology, girls tend to have higher reading efficacy than boys of the same age (Smith, Smith, Gilmore, \& Jameson, 2012). Girls therefore experienced a higher perceived performance in reading comprehension than boys when both groups used printed paper as reading medium in our study. If this explanation is correct, the effects of high ICT efficacy among boys and high reading efficacy among girls canceled each other, resulting in very similar perceived performance on tablets, a fact which may have some application for educators. Grade 6 students displayed no detectable main effects or interaction effects on perceived performance, as the participants all received similar scores. Hypothesis 2 was therefore rejected for grade 6 participants. Based on our results, ICT seems to have no effect on performance and perceived performance in reading comprehension among grade 6 students.

\section{Study 2}

\section{Subjects}

This study comprised 28 grade 1 students from Chan's Creative School (Hong Kong Island). Sixteen of them ( 9 boys and 7 girls) were from class $1 \mathrm{~A}$ and 12 of them ( 7 boys and 5 girls) were from class $1 \mathrm{~B}$. The average academic achievement between the two classes, as reported by the school, was similar. After random selection, class $1 \mathrm{~A}$ served as treatment group and class $1 \mathrm{~B}$ served as control group. The treatment group's age ranged from 6 to $9(M=7.56, S D=0.96)$, while the control group's age ranged from 7 to $9(M=7.62, S D=0.77)$. All participants had made regular individual use of the 7-inch Android 4.0 tablets (Ainol Novo 7 Paladin) in the course of daily class activities for a month. About $61 \%$ of participants had never used tablet technology and all of them had never used tablets for learning in the classroom.

\section{Instruments}

A simple memory test was administered. There were three stages in the test. In the first stage, all participants tried to memorize 25 pictures during a period of 3 minutes. In the second stage, the students performed addition and subtraction exercises for 1 minute as a filler activity to prevent rehearsal of the pictures in their short-term memory. The arithmetic exercises ensured that the participants would be accessing information from long-term memory in the successive recall stage, since information in short-term memory usually decays after about 15 - 20 seconds without rehearsal (Goldstein, 2011). In the third stage, the students were given sheets containing 50 pictures, which included the 25 pictures that they had seen in the first stage and 25 new pictures. Students were asked to identify the 25 pictures that they had attempted to memorize in the first stage of the memory test. All images were chosen from the "Standardized Set of 260 Pictures for Use in Experiments Investigating Differences and Similarities in the Processing of Pictures and Words" (Snodgrass \& Vanderwart, 1980).

\section{Procedure}

Before the experiment started, we obtained informed consent from the school to perform the study using grade 1 students as participants. All procedures discussed in this study were conducted under the guidance of at least one teacher present in the classroom at all times. Participants in the treatment group were given 25 images to view on the Android tablets, while the control group viewed the same 25 images printed on sheets of paper. All participants were asked to memorize the images during a period of 3 minutes, after which they conducted addition and subtraction exercises as filler activity for 1 minute. After that, all participants were handed sheets of paper containing $50 \mathrm{im}$ ages, which included the 25 previously seen images and 25 new images. Students were asked to circle the images that they had attempted to memorize earlier. Images that the students identified correctly counted towards their correct memory score, while falsely recognized selections counted towards their false memory score. The maximum possible score for both correct and false memory for each participant was therefore 25. All received data were used exclusively for the purposes of this research and kept in strict confidentiality; all participating students remained anonymous to researchers. Students' names were not recorded. Data that included any personal identifiers (such as class or class number or handwriting) were destroyed after the results of each procedure were recorded.

\section{Statistical Analysis}

Two two-way independent ANOVAs were conducted to examine the effects of "medium" and "gender" and their interaction effect on correct memory scores and false memory scores. The correct memory score or false memory score were used as the dependent variable in each ANOVA. "Medium" and "gender" were entered as independent variables. Any obtained $p$-value larger than .05 was considered non-significant.

\section{Results}

Table 3 shows the means and standard deviations of both correct memory scores and false memory scores by "medium" (tablet or paper) for male students versus female students. After conducting two-way independent ANOVAs, it was found that students reading on paper had significantly higher correct memory scores than students reading on tablet $(F(1,24)=$ $15.55, p=.001$, partial $\eta 2=.39)$. The main effect of "gender" was non-significant $(F(1,24)=1.57, p=.222)$, meaning that both boys and girls recalled better when the information was presented through the medium of paper. The interaction effect between "medium" and "gender" was also found to be non-significant $(F(1,24)=2.28, p=.144)$, thus the effect of "medium" was not moderated by the effect of "gender" or vice versa.

All main effects and the interaction effect were non-significant when false memory was entered as dependent variable (for "medium": $F(1,24)=1.63, p=.214$; for "gender": $F(1,24)=$ $1.92, p=.179$; for interaction $F(1,24)=0.02, p=.881)$.

\section{Discussion}

Hypothesis 3 was rejected: students remembered materials better when it was presented to them on paper than on Android tablet. This result is inconsistent with the results of Ando and Ueno's (2010) study. This may be due to the difference in methodology between our study and their study: Ando and Ueno (2010) allowed the participants to take notes on-screen, which can be expected to promote memory retention.

Another possible explanation for the lower memory retention we found when reading on tablets is the mismatch in conditions 


\section{EL-MOUELHY ET AL.}

Table 3.

Means, standard deviations, sample sizes, and analysis of variance (ANOVA) results for correct memory scores and false memory scores as a function of medium and gender.

\begin{tabular}{|c|c|c|c|c|c|c|c|}
\hline \multirow[b]{3}{*}{ Medium (Me) } & \multicolumn{4}{|c|}{ Gender (G) } & \multirow{2}{*}{\multicolumn{3}{|c|}{ ANOVA $F(1,24)$}} \\
\hline & \multicolumn{2}{|c|}{ Boys } & \multicolumn{2}{|c|}{ Girls } & & & \\
\hline & $M(S D)$ & $n$ & $M(S D)$ & $n$ & $\mathrm{Me}$ & G & Me x G \\
\hline Correct Memory Scores ${ }^{\mathrm{a}}$ & & & & & $15.55^{* *}$ & 1.57 & 2.28 \\
\hline Reading on tablet & $15.67(3.74)$ & 9 & $15.29(3.07)$ & 7 & & & \\
\hline Reading on paper & $19.29(5.50)$ & 7 & $23.40(1.14)$ & 5 & & & \\
\hline False Memory Scores ${ }^{\mathrm{b}}$ & & & & & 1.63 & 1.92 & 0.02 \\
\hline Reading on tablet & $3.78(4.90)$ & 9 & $1.71(3.68)$ & 7 & & & \\
\hline Reading on paper & $1.86(1.67)$ & 7 & $0.20(0.45)$ & 5 & & & \\
\hline
\end{tabular}

Note. ${ }^{a}$ Correct memory scores ranged from 0 to 25 , higher score indicates more pictures were correctly recognized. ${ }^{b}$ False memory scores ranged from 0 to 25 , higher score indicates more pictures were falsely recognized. $*^{*} p<.001$.

for memory encoding and retrieval. According to Goldstein (2011), "retrieval can be increased by matching the conditions at retrieval to the conditions that existed at encoding" (p. 184). Our treatment group encoded memories by viewing materials on Android tablets, but they retrieved the memories in order to circle their answers on sheets of paper. The control group, on the other hand, encoded and retrieved information in the same medium of paper and could therefore be expected to perform better in the memory test. This explanation can be tested in future studies by comparing the memory test results when reading and testing on tablets with the results when reading on tablet and testing on paper.

\section{General Discussion}

To our knowledge, this is the first study that attempts to meas- ure changes in elementary students' reading comprehension and memory retention when they use the different media of Android tablets and paper. Owing to limited access to the students and time constraints, we were unable to conduct all three types of tests on all participants; grade 4 and 6 students did not take memory tests, and grade 1 students were not tested for reading comprehension and perceived performance. Despite these limi- tations, however, the results of Study 1 led us to conclude that the introduction of low cost Android tablets in the classroom did not have a significant negative impact on grade 6 children's reading comprehension.

Statistical analysis of Study 1 results did not indicate any effect on grade 6 students, whose reading comprehension seemed unaffected by regular exposure to the tablets over the course of one month. Further study is required to establish whether tablets have an effect on the memory retention of grade 6 students. If tablets are found to have no negative effect on students' memory, inexpensive models would represent useful and costeffective additions to the classroom, since they offer a much simpler and lower-maintenance entry point into ICT than conventional personal computers and other apparatus; indeed, even "villagers who have never used a computer before" can learn to use touch-based devices relatively easily (Firth, 2012: p. 6). Some caution, however, was indicated when considering the introduction of tablets to grade 1 and 4 classrooms because in our studies the tablets were associated with some negative effects: compared with the paper-using control groups, grade 1 students using tablets scored lower in memory retention, and grade 4 students using tablets scored lower in reading comprehension. Educators should also consider that, although the use of tablets in the classroom may enhance the confidence of grade 4 boys during reading comprehension tasks, it may also negatively affect the confidence of grade 4 girls engaged in the same activities.

We emphasized that most of the participants were new to Android tablets, and they utilized them for academic purposes in the classroom for only one month. According to Coll, Rochera, and Colomina (2010), the technological characteristics of ICTs would affect the characteristics of the performing task, so in order to perform the task correctly, students need to technologically master the ICTs. It is therefore possible that the negative results we obtain may be due to the children's relative unfamiliarity with the devices, instead of any negative effects inherent in tablet use in the classroom. It is also possible that the particular tablets used in this research, being inexpensive and lacking the features and processing/graphical power of costlier alternatives, may be better suited to drawing, idea generation, and other creative tasks rather than reading comprehension or memorization. The possibility that tablets are more suitable for different types of learning tasks than paper needs to be explored in future research (Ozok et al., 2008). We also recommend further research using tablets in different price ranges, such as "mainstream" or more expensive devices, particularly as tablet technology is improving steadily while costs are dropping. The Google Nexus 7 tablet, which came to market as this paper was being written, was an attractive candidate for future research, being powerful, fully-featured, easily available, and relatively inexpensive.

We would also like to emphasize some limitations in our research. Firstly, as already stated, our access to the school and its students was limited and we were unable to conduct comprehensive testing for all school grades. Secondly, all participants were recruited from Chan's Creative School (Hong Kong Island), a fairly small school, and as a result we faced hard limits on our studies' sample sizes. The limited sample size, all drawn from a single school, means that the generalizability of our 
results to all elementary students in Hong Kong - and beyondis low. Thirdly, the experimental environment was not strictly controlled: students participated in this research in the classroom in the presence of their classmates and not in isolation, which means they were able to discuss the assigned tasks with other participants or use the tablets in various other ways, even though teachers, upon request by experimenters, regularly issued instructions on appropriate experimental conduct and device usage.

A detailed analysis of the economic and social opportunities conferred by exposing young students to ICTs is beyond the scope of this work, however, we consider the subject sufficiently important to warrant some closing words. Investment in ICT education results in children who are familiar with, and develop a facility with, various technologies of ever-increasing relevance. Such investments can be worthwhile, regardless of the exact magnitude of the benefits to academic success if it means that children will become better prepared to take advantage of ICT later in life, academically, economically, and socially. Other researchers have noted "the belief that such investments [in ICT for students] will pay off in the future because the use of technology will lead to educational attainment, and this will lead to employment, earning power and economic activity" (Plowman, Stevenson, McPake, Stephen, \& Adey, 2011: p. 361).

Given the increasing role of social networking services across almost all societies, it is crucial to recognize that the value of ICT for children must not be a purely academic consideration but also a social one: the ability and the skills to safely and effectively utilize a broad range of devices, software and services in a rapidly evolving and highly diverse technological landscape are increasingly important to all persons except very young children, to whom screen-based ICT may be harmful (American Academy of Pediatrics, 2001; House, 2012; Ravichandran \& de Bravo, 2010). As Vryzas \& Tsitouridou (2002) have noted, "in this modern society of rapidly developing technology, children's ability to use ICT is increasingly vital to their success, both in education and in their life afterwards. The necessity of competence in this area is increasingly being recognized" (p. 287).

While it is possible that ICT use in the classroom may include some undesirable effects, educators must weigh eventual disadvantages against the extensive range of benefits conferred. Indeed, it is our position that ICT education is becoming less optional and more mandatory with every advance in the field of high technology. Wheeler (2001) noted that "ultimately, the use of ICT will enhance learning experiences for children, helping them to think and communicate creatively, and work collaboratively. It will also prepare our children for successful lives and careers in an increasingly technological world" (pp. 15-16).

This paper is one of the first empirical studies on the impact of Android tablets on elementary students, providing an initial understanding of the impact of low cost Android tablets on reading comprehension, perceived reading performance and memory retention. The extent of integration of tablet computing into school curricula everywhere remains to be determined, but we strongly encourage other researchers to investigate this subject. We also remind readers that, in spite of improving technology and dropping costs, the digital divide - which can be addressed relatively easily at the elementary school level-remains a serious global concern.

\section{REFERENCES}

American Academy of Pediatrics (2001). Children, adolescents, and television. Pediatrics, 107, 423-426.

http://dx.doi.org/10.1542/peds.107.2.423

Ando, M., \& Ueno, M. (2010). Analysis of the advantages of using tablet PC in e-learning. 2010 10th IEEE International Conference on Advanced Learning Technologies, Nagaoka.

http://dx.doi.org/10.1109/ICALT.2010.42

Animoca (2012). 50 Androids march to school for training day. http://www.animoca.com/en/2012/05/50-androids-march-to-school-f or-training-day/

Baker, R. D. (2010). Comparing the readability of text displays on paper, e-book readers, and small screen devices. Ph.D. Dissertation, Denton: University of North Texas.

BBC News (2000). Gates wants laptop for every pupil. http://news.bbc.co.uk/2/hi/uk_news/education/627182.stm

Bordbar, F. (2010). English teachers' attitudes toward computer-assisted language learning. International Journal of Language Studies, 4, 179206.

Broos, A. (2005). Gender and Information and Communication Technologies (ICT) anxiety: Male self-assurance and female hesitation. Cyber Psychology \& Behavior, 8, 21-31. http://dx.doi.org/10.1089/cpb.2005.8.21

Coll, C., Rochera, M. J., \& Colomina, R. (2010). Situated uses of ICT and mediation of joint activity in a primary education instructional sequence. Electronic Journal of Research in Educational Psychology, 8, 517-540.

Dror, I. E. (2008). Technology enhanced learning: The good, the bad, and the ugly. Pragmatics \& Cognition, 16, 215-223. http://dx.doi.org/10.1075/p\&c.16.2.02dro

Firth, N. (2012). Tablet PCs preserve indigenous knowledge. New Scientist Magazine, 2869.

http://www.newscientist.com/article/mg21428696.400-tablet-pcs-pre serve-indigenous-knowledge.html

Gasparini, A. A., \& Culén, A. L. (2012). Tablet PCs-An assistive technology for students with reading difficulties? The Fifth International Conference on Advances in Computer-Human Interactions (ACHI 2012), Valencia.

http://www.thinkmind.org/index.php?view=article\&articleid=achi_2 01222020083

Goldstein, E. B. (2011). Cognitive psychology (3rd ed.). Belmont, CA: Wadsworth.

Grace, K. E. (2011). Comparing the ipad to paper: Increasing reading comprehension in the digital age. M.D. Thesis, Bowling Green: Bowling Green State University.

Grimshaw, S., Dungworth, N., McKnight, C., \& Morris, A. (2006). Electronic books: Children's reading and comprehension. British Journal of Educational Technology, 38, 583-599. http://dx.doi.org/10.1111/j.1467-8535.2006.00640.x

House, R. (2012). The inappropriateness of ICT in early childhood: Arguments from philosophy, pedagogy, and developmental research. In S. Suggate, \& E. Reese (Eds.), Contemporary Debates in Childhood Education and Development (pp. 105-120). London: Routledge

Hui, A. N. N., \& Lau, S. (2010). Formulation of policy and strategy in developing creativity education in four Asian Chinese societies: A policy analysis. Journal of Creative Behavior, 44, 215-235. http://dx.doi.org/10.1002/j.2162-6057.2010.tb01334.x

Jeong, H. (2012). A comparison of the influence of electronic books and paper books on reading comprehension, eye fatigue, and perception. The Electronic Library, 30, 390-408. http://dx.doi.org/10.1108/02640471211241663

Jones, T., \& Brown, C. (2011). Reading engagement: A comparison between e-books and traditional print books in an elementary classroom. International Journal of Instruction, 4, 5-22.

Kang, Y. Y., Wang, M. J. J., \& Lin, R. (2009). Usability evaluation of E-books. Displays, 30, 49-52. http://dx.doi.org/10.1016/j.displa.2008.12.002

Lucas, B. (2001). Creative teaching, teaching creativity and creative learning. In A. Craft, B. Jeffrey, \& M. Leibling (Eds.), Creativity in Education (pp. 35-44). London: Continuum International Publishing 
Group.

Matthew, K. (1997). A comparison of the influence of interactive CDROM story books and traditional print storybooks on reading comprehension. Journal of Research on Technology in Education, 29, 263275.

Ozok, A. A., Benson, D., Chakraborty, J., \& Norcio, A. F. (2008). A comparative study between tablet and laptop PCs: User satisfaction and preferences. International Journal of Human-Computer Interaction, 24, 329-352. http://dx.doi.org/10.1080/10447310801920524

Plowman, L., Stevenson, O., McPake, J., Stephen, C., \& Adey, C. (2011). Parents, pre-schoolers and learning with technology at home: Some implications for policy. Journal of Computer Assisted Learning, 27, 361-371.

http://dx.doi.org/10.1111/j.1365-2729.2011.00432.x

Ravichandran, P., \& de Bravo, B. F. (2010). Young children and screen time (television, DVDs, computer). National Research Center for Women \& Families.

http://www.center4research.org/2010/05/young-children-and-screentime-television-dvds-computer/

Sheppard, D. (2011). Reading with iPads-The difference makes a difference. Education Today, 11, 12-15.
Smith, J. K., Smith, L. F., Gilmore, A., \& Jameson, M. (2012). Students' self-perception of reading ability, enjoyment of reading and reading achievement. Learning and Individual Differences, 22, 202-206. http://dx.doi.org/10.1016/j.lindif.2011.04.010

Snodgrass, J. G., \& Vanderwart, M. (1980). A standardized set of 260 pictures: Norms for name agreement, image agreement, familiarity, and visual complexity. Journal of Experimental Psychology: Human Learning \& Memory, 6, 174-215.

http://dx.doi.org/10.1037//0278-7393.6.2.174

Stewart, S. (2012). Reading in a technological world: Comparing the iPad to print. M.S. Thesis, Bowling Green: Bowling Green State University.

Vekiri, I. (2010). Boys' and girls' ICT beliefs: Do teachers matter? Computers \& Education, 55, 16-23. http://dx.doi.org/10.1016/j.compedu.2009.11.013

Vryzas, K., \& Tsitouridou, M. (2002). Children and computers: Greek parents' expectations. Educational Media International, 39, 285-297. http://dx.doi.org/10.1080/09523980210166053

Wheeler, S. (2001). Information and communication technologies and the changing role of the teacher. Journal of Educational Media, 26, 7-17. http://dx.doi.org/10.1080/135816500120069292 